\title{
Validating Factors That Impact the Acceptance and Use of e-Assessment among Academics in Saudi Universities
}

\author{
Nuha Alruwais, Gary Wills, and Mike Wald
}

\begin{abstract}
As assessment is one of the important pillars of the learning process, and e-assessment has become an essential part of education systems. E-assessment developed to address some of the limitations and problems of a paper-test. In last the $\mathbf{1 0}$ years, E-assessment has improved in developed countries such as UK. In contrast, in Saudi Arabia, one of the developing countries, less attention is still paid to accept and use of E-assessment and research which discusses $\mathbf{E}$-assessment issues in Saudi Arabia is limited. This paper aims to investigate the factors that has an effect on academics use of E-assessment in Saudi universities. Last study by Alruwais et al. [1] has developed the Model of Acceptance and Usage of E-assessment (MAUE) that has derived from the Decomposed Theory of Planned Behaviour model (DTPB), other theories and models, which investigate the user acceptance and use of ICT, and other related studies. The model consists of the following factors: attitude (perceived ease to use, perceived usefulness, and compatibility), subjective norm (peer influence and superior influence) and perceived behavioural control factors (self-efficacy, resource facilitating conditions, and IT support). Age and gender are also included to the proposed model as moderating factors. In order to refine these factors, interviews were conducted with experts. The results of the interviews show that attitude, subjective norms and perceived behavioural control and its related sub-factors have an influence on academics' intention to use E-assessment. However, experts suggested removing gender and keeping age as a moderating factor. Furthermore, the experts recommended adding awareness of E-assessment as a sub-factor under the attitude factor and including the availability of a security system in the resource facilitating conditions sub-factor.
\end{abstract}

Index Terms-E-assessment, e-exam, electronic exam, online exam.

\section{INTRODUCTION}

Assessment based on using information technology, known as "E-assessment", has become one of the systems introduced to address some problematic issues in traditional assessment. E-assessment is defined as the end-to-end electronic assessment process, where ICT (Information Communication Technology) is used for the whole assessment processes from presenting questions to saving of the leaners responses [2]. E-assessment has successfully provided direct results and feedback, reducing the tutor's time and effort, facilitating the assessment of problem-solving, and improving student performance [3]-[8].

In Saudi Arabia (case of this study), the government provides e-learning courses throughout the National Centre

Manuscript received September 26, 2016; revised December 6, 2016.

The authors are with University of Southampton, UK (e-mail: nma1g14@soton.ac.uk,gbw@ecs.soton.ac.uk,mw@ecs.soton.ac.uk). for e-learning and Distance Learning (NCEDL), which has been established in 2006, under the management of the Higher Education Ministry [9]. E-learning and e-assessment systems are integrated within Saudi educational systems (both in schools and higher education) [10]. There are many studies about E-learning and the acceptance and use of it in Saudi Arabia [9], [11]-[17], but a few of these studies mention E-assessment. There is no research which has discussed the factors that affect the use of E-assessment by academics in Saudi universities. Therefore, this study attempts to identify the factors that affect the academicse willingness to accept and use E-assessment. Last study the authors presented the development model (Model of Acceptance and Usage of E-assessment (MAUE)) (Fig. 1), that investigate the acceptance and use of E-assessment among academics in Saudi universities [1]. The factors of The Model of Acceptance and Usage of E-assessment are derived from models of user acceptance of ICT, specifically Decomposed Theory of Planned Behaviour (DTPB), and other literature reviews. This paper aims to validate the factors in MAUE and searching for new factors impact the use of e-assessment in Saudi Universities, which are not included in MAUE, by interviewing experts from Saudi Universities.

\section{EXPERTS' INTERVIEW STAG}

Interview was designed to investigate the current use of E-assessment, validate the existing factors in the model of Acceptance and Usage of E-assessment and identify new factors.

\section{A. Identifying Experts}

The target experts in this study are the individuals who work with lecturers and at the same time supervise the e-learning in Saudi Universities. In every Saudi University there is a Deanship of E-learning and distance learning, including E-assessment under this Deanship. Therefore, this study aimed to interview all the Deans (or Deputy Deans) of E-learning and distance learning in Saudi Universities in different areas in Saudi Arabia, in order, to obtain different views and opinions. In this study the researchers have interviewed 15 experts from 10 different universities in Saudi Arabia King Saud University, King Abdul Aziz University, Aljouf University, Taif University, Prince Nora University, Taibah University, King Faisal University, Saudi Electronic University, Shaqra University and Tabuk University. The study also covered different cities in Saudi Arabia (Riyadh, Jeddah, Madinah, Taif, Aljouf, Tabuk, Shaqra, and Hofuf).

\section{B. Interview Design}


The aim of the interviews was to explore the extent of use of E-assessment by academic staff in Saudi Universities, and to investigate the existing factors in the Model of Acceptance and Usage of E-assessment. It was also aimed to identify other factors, which are not included in the Model of Acceptance and Usage of E-assessment. Therefore, this study used a semi-structured interview which included both open and closed questions. Open questions were used to obtain an explanation regarding the experts' choices in the closed-ended questions, to identify new factors, and to find out the usage of E-assessment in Saudi Universities.

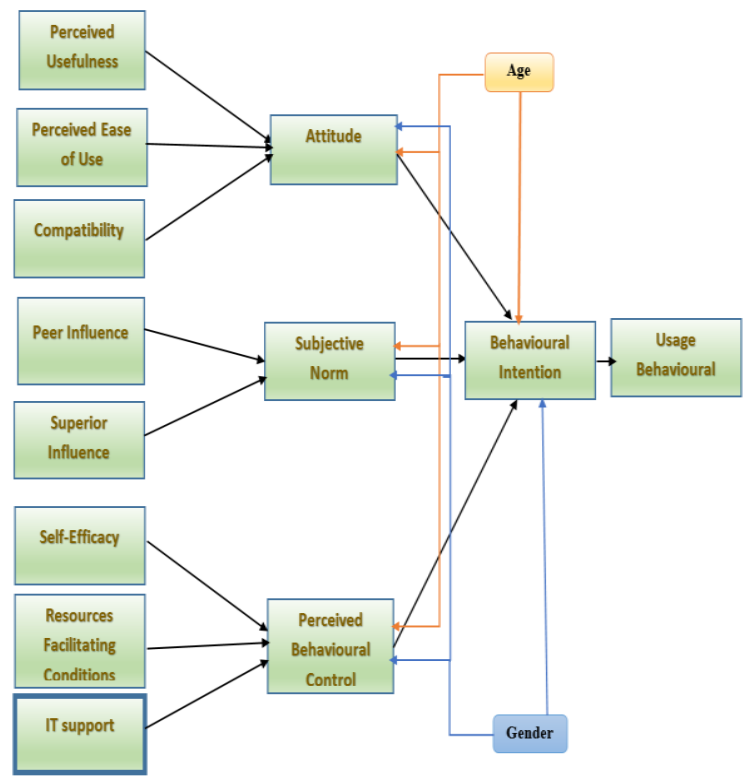

Fig. 1. The model of acceptance and usage of e-assessment.

According to Foddy [18], shorter scales such as five-point scales are desirable in cases where an absolute decision is required. Therefore, a Likert Scale with five-point (strongly disagree, disagree, neutral, agree strongly disagree) was used in this study for the closed-ended questions to investigate the current factors in the model [19]. This was also to ensure the validity of the experts' responses and give them choices to select. The mean intervals in the Likert Scale helped to determine the factors which affect the use and acceptance of E- assessment. The intervals range from 1 to 5 . The mean factor which is $>=3$ is accepted, otherwise the factor is rejected.

The interview questions were validated by two research students and one of the experts. They gave valuable comments which helped to make the questions clearer and more understandable. They did not suggest major changes, just editing some unclear statements. The interviews were conducted in the Arabic language, and the transcripts were translated from Arabic into English. The researcher subsequently of this study asked Arabic researchers at the University of Southampton to confirm accuracy of the translation for both the interview questions and interview transcripts. Additionally, Ethical Approval was needed before starting the interviews. The ethical form for this research has been approved by Ethics Committee at the University of Southampton (research ethics number 1571).

\section{Interview Procedures}

The experts received an e-mail asking them to participate in this research. This e-mail included a brief explanation about the research and its goals, and asked the expert to determine a date and time for the interview. The experts took part in a face-to-face interview with the investigator or interviewed by phone. Each participant was asked to read the participant information sheet and sign the consent form at the beginning of the interview.

After that, the participant was shown the Model of Acceptance and Usage of E-assessment in Saudi Arabia universities and give the opportunity to ask for clarification. This took about 15 minutes. They were asked if the academics in their university use E-assessment?. Next, 16 closed-ended questions were asked to refine the factors and explain the reasons behind their answers. The final open-ended part of the interview consisted of question about improving the model and if they think there are another factors that affect lecturers in Saudi Arabian universities in using E-assessment. This was took about 25 minutes. The total time for the interview was less than 45 minutes. The interviews were recorded.

Some of the experts preferred the interview to be carried out by phone, also, for the experts living in other cities, the phone was used to facilitate the interviews. Consequently, the consent form, information sheet and the model sheet were sent it by e-mail before the time of the interview.

\section{Interview Sample Size}

It is important to interview the right number of experts to obtain significant results. In this stage, determining the minimum sample size is crucial to produce reliable and accurate results [20]. There is no agreed number of experts for an interview in a content validity study; however, most research suggests a panel from 3 to 20 experts [21], [22]. One of the authors suggests using the saturation method [23]. Data saturation in qualitative research means gathering data until reaching a point of redundancy when no new data is being added [24]. The researchers in this study reached redundancy in data gathering during the expert interviews at expert number 15. Consequently, in this study interviews were conducted with 15 experts from different Saudi Universities.

\section{E. Analysis the Interview}

As the information from closed-ended questions is considered as quantitative data, the experts' responses were collected and entered into SPSS software to analyse the data statistically. The One Sample T-test was used to analyse as a statistical test the results of the quantitative data. This test helps in comparing the mean of a population $(\mu)$ with a hypothesised value $(\mu 0)$. The hypothesised mean $(\mu 0)=3$, which indicates Neutral on the five point Likert-type scales. The hypotheses for testing each factor are as follows:

- H0: If the mean rating of the proposed factor is $>=3$, accept the null hypothesis, that the factor is significant, and it affects the use of E-assessment.

- H1: If the mean rating of the proposed factor is < 3, accept the alternative hypothesis, that the factor is not significant, and it does not affect the use of E-assessment. 
The statistical significant level alpha is $\alpha=0.05$. The null hypothesis ( $\mathrm{H} 0)$ is only rejected if the probability (p-value) of question is $\geq \alpha=0.05$. The factor is statistically significant if the p-value $<0.05$, otherwise, the factor is not statistically significant.

\begin{tabular}{|c|c|c|c|c|}
\hline Factor & Sub-factor & Mean & P-value & $\begin{array}{c}\text { Statically } \\
\text { Significant }\end{array}$ \\
\hline \multirow{7}{*}{ Attitude } & \multirow{2}{*}{$\begin{array}{l}\text { Perceived } \\
\text { Usefulness }\end{array}$} & 4.93 & $<0.001$ & Yes \\
\hline & & 4.67 & $<0.001$ & Yes \\
\hline & \multirow[t]{2}{*}{$\begin{array}{l}\text { Perceived } \\
\text { Ease of Use }\end{array}$} & 4.87 & $<0.001$ & Yes \\
\hline & & 4.33 & $<0.001$ & Yes \\
\hline & \multirow[t]{3}{*}{ Compatibility } & 4.93 & $<0.001$ & Yes \\
\hline & & 4.93 & $<0.001$ & Yes \\
\hline & & 4.47 & $<0.001$ & Yes \\
\hline \multirow[b]{2}{*}{$\begin{array}{l}\text { Subjective } \\
\text { Norm }\end{array}$} & Peer Influence & 4.67 & $<0.001$ & Yes \\
\hline & Superior Influence & 4.73 & $<0.001$ & Yes \\
\hline \multirow{5}{*}{$\begin{array}{c}\text { Perceived } \\
\text { Behavioral } \\
\text { Control }\end{array}$} & Self-Efficacy & 4.93 & $<0.001$ & Yes \\
\hline & \multirow{3}{*}{$\begin{array}{l}\text { Resources } \\
\text { Facilitating } \\
\text { Conditions }\end{array}$} & 4.80 & $<0.001$ & Yes \\
\hline & & 4.73 & $<0.001$ & Yes \\
\hline & & 3.80 & $<0.001$ & Yes \\
\hline & IT Support & 4.93 & $<0.001$ & Yes \\
\hline \multirow{2}{*}{ Moderate } & Gender & 2.80 & 0.595 & No \\
\hline & Age & 3.80 & 0.061 & Yes \\
\hline
\end{tabular}

\section{INTERVIEW RESULTS}

\section{A. The Use of e-Assessment by Academics in Saudi Universities}

To find out to what extent the academics use E-assessment in Saudi Universities, experts were asked: Do the academics in your university use E-assessment?

Seven of the experts said "Yes" and eight of them said "No". When research asked for reasons for their answers, some experts who answered "Yes" explained that not all the academics in all their university schools were using E-assessment, most of the academics in mathematics and medical schools were interested in using E-assessment.

"Yes, the health schools more interested using E-assessment compared with the English and Arabic schools" Expert3.

Moreover, Expert 2 clarified one of the obstacles of using E-assessment, which is the security problem or the possibility of cheating if the exam was done at home:

"The lecturers do not use E-assessment unless it is done in the university labs"

About half of the experts said that E-assessment not used in their universities. They provided different reasons such as the fact that the deanship of E-learning was newly established, the Chancellor discouraged academics, and E-assessment was not available for all the academics.

B. Validating Factors in the Model of Acceptance and

\section{Usage of e-Assessment}

The experts were asked questions to investigate the significance of each factor. Table I shows the statistical results of the experts' interview responses.

For the attitude factor and its related sub-factors, the experts indicated that they "strongly agree" that it has an impact on the use of E-assessment by academics. Moreover, the statistical results of the experts' interviews also showed strong significant, the means of these sub-factors were between 4.3 and 4.9 and the p-value for all the questions $<0.05$. The experts provide reasons for their agreements.

Experts 8, 10, 11 and Expert12 confirmed that using E-assessment helps an academic to accomplish his/her tasks quickly:

"Yes, absolutely. For example, the result is released automatically which is faster than manual correction."

Also, one of the expert commented that E-assessment provides automatic corrections which saves lecturers effort:

"It saves the lecturer's effort because it offers automatic correction."

Expert (6) said:

"Yes, it is improving the lecturer's ability to use technology"

Expert15 also supported his answer, commenting:

"Not just for the lecturer, but also for schools and the university. Because paper-test exams cost the university money and effort. The paper test needs writing the questions on paper copying it, monitoring the exam, collecting the paper, correcting it, and releasing the results. This wastes the lecturer's effort and time, but E-assessment just needs to write the questions in the system, and the result will be released automatically."

All of the experts agreed that the background technology is a very important factor that affects the use of E-assessment by academics.

"Yes, absolutely. Some of the lecturers refused to use E-assessment because they don't have the ability to use technology."

"Yes, absolutely, this is the most important factor because lecturers who are not familiar with technology see it is a complex task to do."

The experts agreed that e-assessment is compatible with academics tasks to assess students.

"Yes, absolutely. The E-assessment provides different types of questions. Also, it offers the ability for a lecturer to compare students' answers. " Expert3

"Yes, absolutely. There is a free availability of sorting the questions using E-assessment and there are different properties in the system, for example: it can be used in an essay questions (explain, compare, identify), short answers, multiple answers. But the Chancellor decided that all the lecturers should use objective questions." Expert8.

However, one of the experts commented that it is hard to sort and correct long answer questions, and technical questions using E-assessment.

"Yes, but not that much, because there are some problems in technical support, especially for open questions, but for quizzes E-assessment is very good." Expert4.

As for social factors, the findings of the interviews reveal that peer and superior influence have a high impact on 
academics' behavior to use E-assessment. The means in the quantitative analysis were 4.6 and 4.7 , which is very high, and the p-value for all the questions $<0.05$. Additionally, ten of the experts strongly agreed that social factors have an influence on academics' behavior.

Also, the experts commented that academics can learn how to use e-assessment from each other.

"It will encourage the other lecturers to be as their colleagues. Also, the lecturers who used the E-assessment will show the others how to use the E-assessment and tell them about it benefits."

One of experts suggested collecting the active academics from each school and giving them training courses in using e-assessment. These academics will influence and help to encourage their colleagues in the same school.

"This is possible by collecting some of lecturers from each school and giving them extensive training courses, then they will encourage their colleagues and increase the awareness of E-assessment. Also, they can help the other lecturers to use E-assessment." Expert13.

For the superior influence sub-factor, 12 of experts agree that chancellor has an impact on the academic staff to use E-assessment:

"The Chancellor has a huge impact in encouraging lecturers to use E-assessment." Experts 9,10 and 15.

"In one of Tabuk University's schools, the head was very active and interested to use the system and she encouraged the lecturers in the same school to use the system." Expert15.

Expert11 suggested that the Chancellor should offer rewards for active academics who use E-assessment.

"The Chancellor has a huge impact to encourage lecturers in using E-assessment. They should offer rewards to lecturers who use E-assessment, such as having a course outside the country, or attending a conference."

Regarding perceived behavioural control and its related sub-factors, the quantitative analysis of the interview indicates that this factor is essential to encourage academics to use E-assessment. The means of the questions are between 4.93 and 3.80, which are higher than 3 and the p-value for all the questions $<0.05$. Moreover, the qualitative results show that perceived behavioural control and its related sub-factors has an effect on using E-assessment among academics.

All the experts strongly agreed that having the ability to use E-assessment is essential and providing training courses for academics is crucial to encourage them to undertake E-assessment.

"Yes, absolutely. It is very important"

"Yes, absolutely. For that, we offer training courses especially for adding the questions in the E-assessment system. The training courses are very short-take about half hour and very easy." Expert8.

The exports confirmed that offering a financial reward will encourage academics to use E-assessment.

"Yes, absolutely the reward's so important." Expert1.

"Yes, absolutely. They should offer rewards to lecturers who use E-assessment, such as having a course outside the country, or attending a conference." Expert11

As regards the time, some of the experts agreed that using E-assessment should be counted as part of the working hours and should be mandatory. However, some experts suggested that using rewards would be a solution to encourage academics to use E-assessment, rather than forcing them.

"It is very difficult to enforce the lecturers to use E-assessment, but if there are rewards that will encourage lecturer to use E-assessment. For example, some universities offer financial rewards about $20 \%$ if the lecturers use Blackboard and update their webpage. But cutting an amount from a lecturer's salary to enforce them to use E-assessment is impossible in Saudi universities." Expert9.

In the expert review, it is noticeable that IT support is a very important sub-factor, as none of the experts disagreed that "IT support is essential to help academics to use E-assessment", and all the experts selected the "strongly agree" choice, and they commented:

"Yes, absolutely. It is very important."

The experts commented that IT support is the reason behind the successful projects, and it guarantees continued use of E-assessment:

"Yes, absolutely. The technical support is the secret of system or project success, and it should be immediate and continuous support." Expert10.

"It is very important, because it ensure the continuity to use E-assessment." Expert13.

Regarding the moderating factors (age and gender), experts expressed the view that age can have an impact on academics' use of E-assessment, while gender does not affect the use of E-assessment. The statistical analysis of the moderating factors (Table I) shows that the mean of the age question is 3.80 , while the mean of the gender question is 2.80 , which is less than 3 . Therefore, age is considered as moderating factor and gender is rejected. Moreover, the qualitative analysis of moderating factors confirmed the results of quantitative analysis. Some of the experts agreed that age can affect use and acceptance of E-assessment:

"Yes. Most of the old lectures refused to use technology." Expert15.

"Yes, in general the young lecturers are more interested to use E-assessment” Expert4.

While, eleven of the experts refused to consider gender as a factor that can affect use of E-assessment by academics in Saudi Universities.

"No, there are no differences between male and female " Experts 4,7,8.

"No different" Experts10, 12.

The qualitative and quantitative results confirmed that all the factors and sub factors in the Model of Accaptance and Usage of E-assessment have an impact on academic staffs in Saudi Universities, except the gender moderating factor. The experts recommended to remove gender from the model.

\section{Suggested Factors}

The researcher asked the experts if they are aware of other factors, which are not included in the MAEU, and can affect the use of E-assessment. Some of the experts did not add any factors, but two factors were suggested by some others:

1) Awareness of the e-assessment and it benefits.

2) Confidence in e-assessment (in terms of security).

The most important new factor, which nine of the experts recommended to be added to the model, is "e-assessment awareness". They pointed out that awareness of e-assessment 
has beneficial effect on academics' attitude towards using the system. Therefore, e-assessment awareness becomes a sub-factor under the attitude factor. Also, some experts mentioned that academics do not use E-assessment, because they do not trust the security system. They said the university should provide a secure system to encourage lecturers to use it, and to avoid cheating in exams. Therefore, system security is added under the resources facilitating conditions sub-factor.

Fig. 2 shows the MAEU (Model of Acceptance and Usage of E-assessment) after editing according to the results of the experts' interviews.

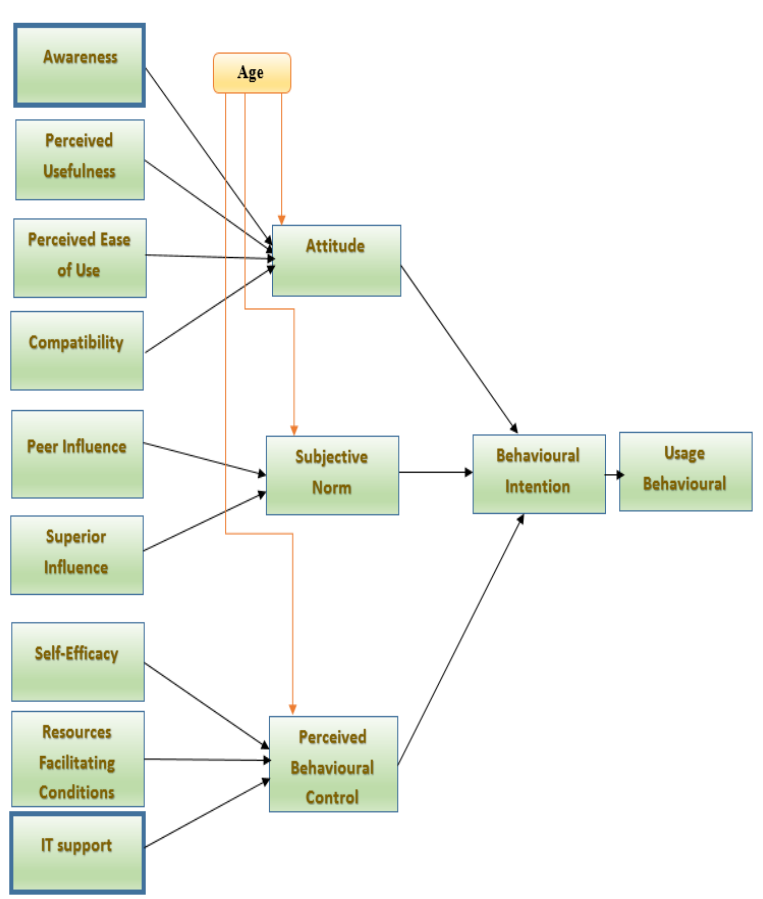

Fig. 2. The model of acceptance and usage of e-assessment.

\section{CONCLUSION}

This paper has investigated the validity of the existing factors that were included in the Model of Acceptance and Usage of E-assessment, and the extent to which E-assessment is currently used in Saudi Universities. Experts were interviewed to examine the factors. Both quantitative and qualitative methods were used to ensure the validity of the factors. The results from the interviews with experts' show that attitude, subjective norm and perceived behavioural control are significant factors that have an impact on the use E-assessment in Saudi Universities. The experts also believed that age may impact academics use of E-assessment, but gender does not have this influence. Moreover, they suggested including 'awareness' as a sub-factor affecting the academics' attitude, and "security system" under resource facilitating conditions.

\section{FUTURE WORK}

Another step is considered to validating the Model of Acceptance and Usage of E-assessment. The next step will be distributing questionnaire to all academics in different universities in Saudi Arabia. This is to confirm the result from experts' interviews. To ensure that factors in MAUE are likely to have an influence on lecturers' use of E-assessment in Saudi Universities, and to identify the factors which have the strong effect on the lecturers' intention to use e-assessment.

\section{ACKNOWLEDGEMENT}

This research supported by University of Southampton, and the Fundamental Research Funds for Saudi Culture Mission in UK. Their support and consideration are highly appreciated.

\section{REFERENCES}

[1] N. Alruwais, G. Wills, and M. Wald, "Identifying factors that affect the acceptance and use of e-assessment by academics in Saudi Universities," IJAEDU- Int. E-Journal Adv. Educ., vol. 2, no. 4, pp. 132-140, 2016.

[2] Joint Information Systems Committee (JISC), "Effective practice with e-assessment," 2007.

[3] J. Ridgway, S. McCusker, and D. Pead, "Literature review of e-assessment," Bristol, 2004.

[4] T. B. Crews and D. F. Curtis, "Online course evaluations : Faculty perspective and strategies for improved response rates," Assessment \& Evalution in Higher Education, vol. 36, no. 7, pp. 965-878, 2010.

[5] J. W. Gikandi, D. Morrow, and N. E. Davis, "Online formative assessment in higher education: A review of the literature," Comput. Educ., vol. 57, no. 4, pp. 2333-2351, Dec. 2011.

[6] L. Gilbert, D. Whitelock, and V. Gale, "Synthesis report on assessment and feedback with technology enhancement," Southampton, 2011.

[7] A. Way, "The use of e-assessments in the Nigerian Higher Education system," Turkish Online J. Distance Educ., vol. 13, no. 1, pp. 140-152, 2012.

[8] E. Sorensen, "Implementation and student perceptions of e-assessment in a chemical engineering module," Eur. J. Eng. Educ., vol. 38, no. 2, pp. 172-185, Jan. 2013.

[9] A. Almegran, A. Al-Yafei, and H. Ahmad, "Pilot nationwide e-learning provision in the Kingdom of Saudi Arabia: Issues and challenges," presented at 21st Asian Association of Open Universities' Annual Conference, 2007.

[10] Y. Hakami, A. Razak, C. Husin, and S. Tam, “A CBT framwork For secondary schools of Saudi," Sci.Int, no. 1, pp. 853-864, 2014.

[11] B. Yushau, "The effects of blended e-learning on mathematics and computer attitudes in pre-calculus algebra," Tmme, vol. 3, no. 2, pp. 176-183, 2006.

[12] A. Mirza, "Is e-learning finally gaining legitimacy in Saudi Arabia," Saudi Comput. J., vol. 6, no. 2, 2007.

[13] F. N. Al-Fahad, "Students' attitudes and perceptions towards The effectiveness of mobile learning in King Saud Uinversity, Saudi Arabia," Turkish Online J. Educ. Technol. TOJET, vol. 8, no. 2, 2009.

[14] R. Alebaikan and S. Troudi, "Blended learning in Saudi universities Challenges and perspectives," Alt-J, vol. 18, no. 1, pp. 49-59, Mar. 2010.

[15] A. Alenezi, A. Abdul Karim, and A. Veloo, "An empirical investigation into the role of enjoyment, computer anxiety, computer self-efficacy and internet experience in influencing the students' intention to use e-learning: A case study from Saudi Arabian governmental universities," Turkish Online J. Educ. Technol., vol. 2, no. 4, pp. 22-34, 2010

[16] A. M. Al-Shehri, "E-learning in Saudi Arabia: 'To E or not to E, that is the question,"” J. Fam. Community Med., vol. 17, no. 3, pp. 147-150, 2010 .

[17] H. Alkhalifa, "E-learning and ICT integration in colleges and universities in Saudi Arabia," E-learn Magazine, 2010.

[18] W. Foddy, Constructing Questions for Interviews and Questionnaires: Theory and Practice in Social Research, Cambridge, UK: Cambridge University Press, 1993.

[19] R. Likert, "A technique for the measurement of attitudes," Arch. Psychol., vol. 22, p. 140, 1932.

[20] A. Banerjee, U. B. Chintnis, S. L. Jadhav, and S. Chaudhury, "Hypothesis testing, type I and type II errors," Ind. Psychiatry J., vol. 18, no. 2, p. 127, 2009.

[21] J. S. Grant and L. L. Davis, "Selection and use of content experts for instrument development.," Res. Nurs. Health, vol. 20, pp. 269-274, 1997. 
[22] M. R. Lynn, "Determination and quantification of content validity," Nursing Research, vol. 35. pp. 382-385, 1985.

[23] B. Marshall, P. Cardon, A. Poddar, and R. Fontenot, "Does sample size matter in qualitative research?: A review of qualitative interviews in is research," J. Comput. Inf. Syst., pp. 11-22, 2013.

[24] G. a. Bowen, "Naturalistic inquiry and the saturation concept: A research note," Qual. Res., vol. 8, no. 1, pp. 137-152, 2008.

Nuha Alruwais is a $\mathrm{PhD}$ student in electronics and computer science at University of Southampton, UK and lecturer assistance in King Saud University in Riyadh, Saudi Arabia. She received her B.Sc. degree in computer science from King Saud University, and her M.A degree in information system from University of Sydney.

Gary Wills is an associate professor in computer science at University of Southampton, UK. He graduated from the University of Southampton with an Honors degree in electromechanical engineering, and then a $\mathrm{PhD}$ in industrial hypermedia systems. He is a chartered engineer, a member of the
Institute of Engineering Technology and a Principal Fellow of the Higher Educational Academy. $\mathrm{He}$ is also a visiting associate professor at the University of Cape Town and a research professor at RLabs.

Mike Wald is a professor in University of Southampton, UK. He leads research into accessible technologies in the Web and Internet Science Research Group, ECS and has advised HEFCE, JISC, BECTA and Universities on enhancing learning through the use of technologies. He established the University's MSc in computer based learning and Centre for Enabling and Learning Technologies (CELT) in 1994 and was involved in the establishment of the University's Disability and Assistive Technology Services. He is a founder member of the International Liberated Learning Consortium that includes other leading universities (e.g. MIT) and organizations (e.g. IBM, Nuance) and is investigating how speech recognition can make teaching and learning more accessible. 